\title{
Usefulness of cell-mediated immune function in risk stratification for patients with advanced heart failure(Article)
}

- Nagarajan, V. ,

- Hernandez, A.V. ${ }^{\mathrm{bc}}$,

- Cauthen, C.A. ${ }^{d}$,

- Starling, R.C. ,

- $\quad$ Tang, W.H.W. ${ }^{e}$ Email Author

- View Correspondence (jump link)

- $\quad$ aDepartment of Cardiology, University of Texas Medical Branch, Galveston, Texas, United States

- $\quad$ bepartment of Quantitative Health Sciences, Lerner Research Institute, Cleveland, $\mathrm{OH}$, United States

- 'School of Medicine, Universidad Peruana de Ciencias Aplicadas (UPC), Lima, Peru

View additional affiliations_

Abstract_View references (22)

Although heightened inflammation and autoimmune responses have been well described in patients with heart failure, the role of cell-mediated immune function in the pathogenesis and progression of heart failure is unclear. The aim of our study is to evaluate the prognostic role of cell-mediated immune function in patients with advanced heart failure. Methods We studied patients with advanced heart failure referred for evaluation of candidacy for advanced heart failure therapies between 2007 and 2010. Cell-mediated immune response was categorized into 3 groupslow or poor immune response $(\leq 225 \mathrm{ng} / \mathrm{mL})$, moderate or normal immune response $(226-524 \mathrm{ng} / \mathrm{mL})$, and strong immune response $(\geq 525 \mathrm{ng} / \mathrm{mL})$ —using a phytohemagglutinin-stimulated T-cell response assay. Results Out of 368 patients, 41 patients $(11.1 \%)$ had poor immune function, 258 patients $(70.1 \%)$ had normal immune function, and 69 patients (18.7\%) had strong immune function. The primary outcome of all-cause mortality or cardiac transplantation occurred in $63.4 \%, 45.3 \%$, and $34.8 \%$ in the poor immunity, normal immunity, and strong immune function groups, respectively. In univariate analysis, cell-mediated immune function was strongly associated with the primary outcome $(P=.014)$. Poor immune function portended worse prognosis (hazard ratio $=2.18,95 \% \mathrm{Cl} 1.01-4.70, \mathrm{P}$ $=.047$ ), and strong immune function was associated with better survival (hazard ratio $=0.67,95 \% \mathrm{Cl} 0.43-1.04$ ). However, when adjusted for multiple variables in multivariate analysis, immune function status lost its overall significance to predict primary outcome $(P=0.11)$, but the direction to an increased risk of primary outcome was maintained in the poor immune function group. Conclusions Poor cell-mediated immune function measured by a clinically available assay could be 
associated with more adverse long-term prognosis in patients with advanced heart failure. (C) 2016 Elsevier Inc.

Reaxys Database Information

(1) View Compounds

Indexed keywords

EMTREE drug terms:

acetylsalicylic acidangiotensin receptor antagonistbeta adrenergic receptor blocking ag carboxypeptidase inhibitorhydralazinenitric acid derivativephytohemagglutininspironol

EMTREE medical terms: adultArticlecardiac patientcardiovascular mortalitycellular immunityfemaleheart failure transplantationhumanmajor clinical studymalemedical record reviewpriority journalpro failureimmunologyKaplan Meier methodmiddle agedmortalityproceduresrisk assessmeı

MeSH: AdultAgedHeart FailureHumansImmunity, CellularKaplan-Meier EstimateMaleMiddle $A_{\varepsilon}$

Chemicals and CAS Registry Numbers:

acetylsalicylic acid, 493-53-8, 50-78-2, 53663-74-4, 53664-49-6, 63781-77-1; clopidogrel, 113665-84-2, 120202-66-6, 90055-48-4, 94188-84-8; hydralazine, 304-20-1, 86-54-4; phytohemagglutinin, 9008-97-3; spironolactone, 52-01-7

Funding details

Funding number Funding sponsor

RO1 HL103931

National Institutes of Health

Funding text

Funding support: There is no extramural funding for this project. Dr Tang is funded by grants from National Institutes of Health (RO1 HL103931).

- ISSN: 00028703

- CODEN: AHJOA

- Source Type: Journal

- Original language: English

- DOI: 10.1016/j.ahj.2016.09.008

- PubMed ID: 27979039

- Document Type: Article

- Publisher: Mosby Inc. 
